\title{
Weather, climate, and hydrologic forecasting for the US Southwest: a survey
}

\author{
Holly C. Hartmann*, Roger Bales, Soroosh Sorooshian \\ Department of Hydrology and Water Resources, University of Arizona, Tucson, Arizona 85721, USA
}

\begin{abstract}
As part of a regional integrated assessment of climate vulnerability, a survey was conducted from June 1998 to May 2000 of weather, climate, and hydrologic forecasts with coverage of the US Southwest and an emphasis on the Colorado River Basin. The survey addresses the types of forecasts that were issued, the organizations that provided them, and techniques used in their generation. It reflects discussions with key personnel from organizations involved in producing or issuing forecasts, providing data for making forecasts, or serving as a link for communicating forecasts. During the survey period, users faced a complex and constantly changing mix of forecast products available from a variety of sources. The abundance of forecasts was not matched in the provision of corresponding interpretive materials, documentation about how the forecasts were generated, or reviews of past performance. Potential existed for confusing experimental and research products with others that had undergone a thorough review process, including official products issued by the National Weather Service. Contrasts between the state of meteorologic and hydrologic forecasting were notable, especially in the former's greater operational flexibility and more rapid incorporation of new observations and research products. Greater attention should be given to forecast content and communication, including visualization, expression of probabilistic forecasts and presentation of ancillary information. Regional climate models and use of climate forecasts in water supply forecasting offer rapid improvements in predictive capabilities for the Southwest. Forecasts and production details should be archived, and publicly available forecasts should be accompanied by performance evaluations that are relevant to users.
\end{abstract}

KEY WORDS: Weather forecasts · Climate forecasts $\cdot$ Hydrologic forecasts $\cdot$ US Southwest $\cdot$ Hydrometeorology $\cdot$ Hydroclimatology

Resale or republication not permitted without written consent of the publisher

\section{INTRODUCTION}

Whether explicitly recognized or not, most decisions related to natural resource management rely on of some sort of weather, climate, or hydrologic forecast. The forecasts may be produced by teams of experts using many kinds of data, sophisticated mathematical representations of physical processes, and complex objective techniques for combining results. Alternatively, an individual may rely on simple, subjective, ad hoc forecasting processes; they may simply have a feeling, based on an implicit assumption that future

*E-mail: hollyh@hwr.arizona.edu conditions will be much like the past. In between these extremes exists a continuum of forecast methods, including simple statistical techniques based on limited data and complex subjective heuristics.

The ubiquitous role of hydrometeorologic forecasts made them an important component of the Climate Assessment for the Southwest (CLIMAS) project (Bales 2002, in this issue), an integrated assessment of climate vulnerability. Good forecasts enable decision makers to effectively plan proactive responses to potential climate events (Changnon \& Vonnhame 1986, Changnon et al. 1999), but use of poor forecasts can produce dire consequences (Glantz 1982). Interactions with different groups in the Southwest (e.g. Benequista \& James 
1998, Conley et al. 1999, Pagano et al. 2002, in this issue) repeatedly demonstrated that many users did not clearly understand what kinds of forecasts were available, how they were intended to be interpreted, or how well past predictions had matched reality. Further, as highly interdisciplinary efforts, integrated assessments require a shared foundation of understanding across many social and physical science disciplines (Liverman \& Merideth 2002, in this issue). Not unexpectedly, many researchers joined CLIMAS having only limited knowledge of hydrometeorologic forecasts. However, our discussions with members of the hydrometeorologic community consistently revealed discrepancies in their understanding of forecast availability, procedures, interpretation, and performance.

This paper surveys the weather, climate, and hydrologic forecasting situation existing in the US Southwest, with 3 main objectives: (1) To document the diversity of forecasting entities, available products, and avenues of access that existed during a specific period, which can serve as a baseline for evaluating subsequent advances in the production and delivery of forecasts. (2) To provide an efficient introduction, suitable for a broad interdisciplinary audience, to forecasts and issues concerning their production, communication, and evaluation. (3) To identify directions for rapidly advancing the state of hydrometeorologic forecasting in ways relevant to scientific researchers, operational forecasters, potential users, and integrated assessments.

\section{METHODS}

This survey synthesizes material from 3 types of sources: historic and current forecasts, forecasting personnel, and the scientific literature. Descriptions of forecast characteristics were developed using qualitative analyses of multiple lines of evidence. Informational inconsistencies were resolved, where possible, by relying on information accompanying the most recent forecasts or by interviewing personnel involved with the specific issue. Material was collected from April 1998 through March 2000.

Actual forecasts and their ancillary information served as primary source material. Although some forecasts were archived in printed form, many were transient and available primarily, if not exclusively, on the World Wide Web. Source material was identified through recommendations of agency personnel and forecast users and use of multiple Web search engines. While this study attempted comprehensive coverage of hydrometeorologic forecasts relevant to the Southwest, particular emphasis was given to products issued by the National Weather Service (NWS) due to their role as the official federal forecasting agency. Hartmann et al. (1999) documented details about the forecasts, including then-current Web addresses, although ephemeral materials are not retrievable. In addition, example forecast products are archived and available upon request.

This study also relied on extensive interaction with key personnel from agencies involved in producing or issuing forecasts, providing data for making forecasts, or serving as a link for communicating forecasts. Individuals were selected based on our understanding of the forecasting milieu and recommendations by others, including the solicited personnel. Significant material was obtained through a workshop (Institute for the Study of Planet Earth, University of Arizona, Tucson, 8-9 July 1998) that involved the NWS Weather Forecast Offices (WFOs) of Phoenix and Tucson, NWS Colorado Basin River Forecast Center (CBRFC), NWS Office of Hydrology, Natural Resources Conservation Service (NRCS), Bureau of Reclamation, Salt River Project (SRP), Western Regional Climate Center (WRCC), and National Oceanic and Atmospheric Administration (NOAA) Office of Global Programs, as well as academic institutions. The workshop relied on focused discussions to address predetermined topics (Whyte 1977, Rubin \& Rubin 1995). In addition, experts were invited to describe various aspects of forecasting in a special session and panel discussion at the 1999 Spring Meeting of the American Geophysical Union (AGU 1999). Extended discussions were also conducted with key personnel from the NWS Climate Prediction Center (CPC). Subsequent discussion and correspondence were targeted at filling information gaps about forecast procedures, interpretation, and other issues. To protect confidentiality (Dunn \& Chadwick 1999), comments are not attributed to specific participants; however, discussion notes are archived.

This survey is conceptually organized into 3 broad categories: weather, climate, and hydrologic forecasts. The temporal boundary between weather and climate is indistinct and was sometimes a point of disagreement within the forecast and research communities. This survey uses the CPC (1995) definition, which considered weather forecasts to cover periods shorter than 1 mo and climate forecasts to cover periods 1 mo and longer. Hydrologic forecasts cover both time scales due to the integrative character of hydrologic processes (e.g. snowmelt peak streamflow forecasts refer to short-term conditions, but reflect the hydrologic response to melt of seasonal snowpack accumulation). Quantitative precipitation forecasts (QPFs) are included herein as hydrologic forecasts, because they were produced specifically as inputs for flood forecasts and were typically considered hydrologic forecasts during discussions with agency personnel. 


\section{WEATHER FORECASTS}

\subsection{Forecast products and providers}

Weather forecasts examined during this survey encompassed a tremendous variety of types covering multiple spatial and temporal scales and were available from myriad sources (Table 1). They typically tracked the movement and evolution of specific air masses in order to predict meteorologic quantities (e.g. daily maximum and minimum air temperatures) or the occurrence of events (e.g. precipitation, tornadoes).

The NWS had 2 official delivery mechanisms for their forecasts during the survey period: the NOAA Weather Radio and Weather Wire Service. However, they supported others, including the NOAA Family of Services, Weather by Telephone, the Emergency Managers Weather Information Network (EMWIN), and the Web. NWS units maintained their own Web sites; the look and feel of each site were vastly different, with varying ease of product access.

The NWS reorganization, completed in 1999 (C. O'Hara 1999: www.fcw.com/fcw/articles/1999/fcw _ 080299_894.asp), generally shifted responsibilities for producing and issuing official weather forecasts to a greater number of local WFOs; 11 WFOs provided coverage for the Southwest, including the Colorado River basin. Routine general products from the WFOs consisted of brief text and tabular products presenting, at minimum, predictions of high and low temperatures, likelihood of precipitation, and wind direction and speed. They were usually issued twice daily, but updated more frequently when rapidly changing conditions warranted. Zone forecasts typically covered portions of counties (e.g. 40 zones in Arizona), while state forecasts covered larger regions (e.g. 6 regions in Arizona). Area forecast discussions were unique among routine products. They used technical terms and cryptic abbreviations, but presented the rationale WFO forecasters used in making a specific forecast, including recent performance of numerical weather models, unique conditions underlying skepticism or confidence in model results, conditions creating forecast difficulty and uncertainty, and prospects for improved or deteriorating predictability. In 1998, the Tucson, Arizona, WFO began to experimentally issue Southeast Arizona Convective Outlooks each afternoon during the summer monsoon season. They differed from routine products by forecasting thunderstorm areal coverage and location, expected direction of motion, and conditional probabilities of storm severity and precipitation totals.

When faced with prospective extreme weather conditions, WFOs could issue a variety of special purpose forecasts for locations (e.g. canyon areas known for hazardous driving during high winds) within their county warning areas, and they had the responsibility for issuing official warnings for severe thunderstorms and tornadoes. However, the NWS Storm Prediction Center had the responsibility for issuing official watches for severe thunderstorms and tornadoes, which were then transmitted by affected WFOs through their usual mechanisms, creating the need for intensive communication and coordination among national, regional, and local NWS units. Similar relationships existed between WFOs and the NWS National Hurricane Center regarding infrequent tropical storms and hurricanes affecting the Southwest.

The CPC was responsible for the NWS threats assessment, which transitioned from 'experimental' to 'operational' status during the study period. The forecasts consisted of weekly graphical products, sometimes supplemented with daily text updates, describing the potential for extreme hydrometeorologic conditions (e.g. extreme heat or heavy rains) based on NWS medium- ( 3 to $5 \mathrm{~d}$ ), extended- (6 to $10 \mathrm{~d}$ ), and long- (monthly and seasonal) range forecasts, as well as hydrologic forecasts.

Forecasts from non-WFO NWS, NOAA, Department of Defense, and National Aeronautical and Space Administration units and several universities were routinely accessible to the public, although they were generated to provide guidance to the WFOs in creating local forecasts or to support internal operations, including research activities. These products were highly varied in content, complexity, and clarity of communication, but typically simply provided output from individual numerical weather models.

Commercial forecasts consisted of 2 types: free and fee- or subscription-based. Free forecasts were often associated with providers deriving revenue from advertising (e.g. The Weather Channel) or were offered as an inducement to cost-based forecasts (e.g. Baja Weather Service). Costs were typically associated with unique types of forecasts for user-specified locations. Some custom forecasts ultimately appeared in newspapers and on television and radio. Some vendors targeted specific markets by offering 'one-stop shopping' for easy access to forecasts, along with other market-sector information (e.g. Weather Sites, Fox Weather). Often, free forecasts were simply copies of official NWS forecasts or products available from other providers, although they sometimes included only portions of the original forecast and ignored essential ancillary products (e.g. text discussions, forecast category definitions). Unisys transformed NWS weather model results into attractive graphical products, citing the NWS as the data source; however, it was not clear that the product represented intermediary NWS information, not an official forecast. SRP produced temper- 
ature and relative humidity forecasts primarily for internal power generation and marketing operations, but through cooperative agreements, provided some products to outside clients, including government agencies (e.g. advisories for lightning, high winds, and heavy rains for the Phoenix, Arizona, area). The Old Farmer's Almanac, an annual magazine, was unique in providing weather forecasts (e.g. 'stormy', 'sunny') with lead times of more than a year in advance; while the forecasts were not based on modern scientific

Table 1. Weather forecasts available with Southwest US coverage, April 1998 to March 2000. NOAA: National Oceanic and Atmospheric Administration; NASA: National Aeronautical and Space Administration

\begin{tabular}{|c|c|}
\hline Forecast producers and providers & Forecast products \\
\hline Government agencies & NWS products \\
\hline National Weather Service (NWS) & Routine general products $(1-3 \text { d coverage })^{\mathrm{d}}$ \\
\hline Weather Forecast Offices & Local forecasts \\
\hline Storm Prediction Center & Zone forecasts \\
\hline National Hurricane Center & State forecasts \\
\hline Climate Prediction Center & Area forecast discussions \\
\hline Hydrometeorological Prediction Center & \\
\hline Aviation Weather Center & Special-purpose products (min to h coverage) \\
\hline Air Resources Laboratory/NOAA & Short-term forecasts \\
\hline Forecast Systems Laboratory/NOAA & Watches and warnings \\
\hline National Severe Storms Laboratory/NOAA & Severe thunderstorms \\
\hline Global Hydrology and Climate Center/NASA & Winter storms \\
\hline Naval Research Laboratory & Tornadoes \\
\hline Air Force Weather Agency & Aviation \\
\hline $\begin{array}{l}\text { Air Force Weather Agency } \\
\text { Western Regional Climate Center (WRCC) }{ }^{a}\end{array}$ & Marine \\
\hline Western Regional Climate Center (WRCC) ${ }^{\mathrm{a}}$ & Weather advisories (e.g. wind, heat, fog) \\
\hline Bureau of Reclamation & Special weather statements \\
\hline Natural Resources Conservation Service & Significant weather outlooks \\
\hline Universities & Urgent weather messages \\
\hline Colorado State University & Miscellaneous (highly variable coverage) \\
\hline Pennsylvania State University & Aviation terminal forecasts \\
\hline University of Arizona & Domestic aviation en route forecasts \\
\hline University of Utah & Marine forecasts \\
\hline University of Washington & Fire weather forecasts \\
\hline Commercial entities $^{b}$ & Selected cities/traveler's forecasts \\
\hline Media outlets & Threats assessment \\
\hline USA Today & Drought monitor \\
\hline Local newspapers & Southeast Arizona convective outlook \\
\hline Radio stations & Extended forecasts $(3-5,6-10,8-14 \mathrm{~d})$ \\
\hline Local television stations & Commercial products \\
\hline $\begin{array}{l}\text { The Weather Channel } \\
\text { Cable News Network (CNN) }\end{array}$ & City forecasts $(1.5,5,10,14 \mathrm{~d})^{\mathrm{d}}$ \\
\hline $\begin{array}{l}\text { Cable News Network (CNN) } \\
\text { AccuWeather }\end{array}$ & Threat alerts (e.g. wind, heat, fog, storms) \\
\hline Baja Weather Service & Agriculture forecasts \\
\hline Compu-Weather & Frost alerts and warnings \\
\hline Fox Weather & Fruit harvest forecasts \\
\hline Kavouras, Inc. & Soil moisture forecasts \\
\hline Kavouras, Inc. & Cloud cover forecasts \\
\hline Unisys & Marine forecasts \\
\hline Weather Sites, Inc. & Recreation, port, shipping route forecasts \\
\hline Salt River Project (SRP) ${ }^{\mathrm{C}}$ & Aviation forecasts \\
\hline The Old Farmer's Almanac & Film industry forecasts \\
\hline Private non-commercial entities & Ski resort forecasts \\
\hline Amateur forecasters & Ultraviolet radiation recreation forecasts \\
\hline Hobbyists & Utilities (e.g. power, transportation) forecasts \\
\hline
\end{tabular}

${ }^{\mathrm{a}} \mathrm{WRCC}$ includes state and academic partners

bInclusion does not imply endorsement of vendor services or products

'SRP has public and private components

${ }^{\mathrm{d}}$ Maximum and minimum temperatures and precipitation, sometimes winds, relative humidity 
theory, they were consistently recognized as a forecast source by members of the general public (Hartmann 2001).

Some governmental entities (e.g. WRCC, NRCS) operated much like commercial vendors, using the Web to provide one-stop shopping by linking to or reformatting NWS products and offering unique free or subscription-based products. As such, their products had similar caveats; in addition, continuity of agency efforts was poor, with many outdated products. Unique products included the Bureau of Reclamation's daily forecasts of daily precipitation depth and Penman evaporation offered via their Web-based Agricultural Water Resources Decision Support (AWARDS) System.

\subsection{Forecast techniques}

Weather forecasts encountered in this study were typically generated using complex, non-linear, dynamic numerical models describing physical interactions between solar radiation and atmosphere, ocean, and land systems. In making an official forecast, WFO meteorologists subjectively combined results from many models (Table 2), some generated by non-NWS entities, with recent local observations and accumulated personal experience. The models differed in their spatial and temporal resolutions, internal structures, process descriptions, and parameterizations. Using variations of recent observations and model character- istics, repeated model runs were used to generate multiple outputs, comprising an ensemble of forecasts. Models were often interdependent, as some provided boundary conditions for others, had multiple implementations, or were also subjectively combined prior to WFO access. Details of the specific variables used, variations in starting conditions, number of model runs, and model run lengths were highly variable and often difficult to explicitly determine from available documentation.

Many non-WFO forecast producers presented results from individual numerical models as stand-alone weather forecasts, although WFO forecasters considered them only as 'sensible weather guidance'. An exception was SRP, which operated like a WFO. In general, private-sector forecast providers had proprietary interest in their techniques and typically withheld descriptions of their specific methods.

The numerical weather models listed in Table 2 changed frequently (sometimes almost monthly) throughout the study period. Some model adjustments were systemic, providing greater model resolution, larger areal coverage, longer model runs, shifted model run schedules, or diversification of model outputs. Others corrected process parameters to improve model performance for a specific region or type of condition. Notifications of model modifications were distributed as public information statements using the NWS's standard delivery mechanisms, but the comprehensiveness of readily available archived documentation was erratic.

Table 2. Numerical models used to produce National Weather Service weather forecasts, April 1998 to March 2000 . Not all models used in a single forecast; selection of models and outputs determined by forecasters

\begin{tabular}{|lc|}
\hline Model name and acronym & Sources \\
\hline Nested Grid Model (NGM) & Hoke et al. (1989) \\
Eta Models (Eta, meso-Eta, Eta-10) & Janzic (1994), Rogers et al. (1995), Staudenmaier \\
& $(1996 \mathrm{a}-\mathrm{d}, 1997 \mathrm{a}-\mathrm{C})$, Mittlestadt (1997) \\
Aviation (AVN) Model & Kalnay et al. (1990) \\
Medium Range Forecast (MRF) Model & National Meteorological Center (1988), Kalnay et \\
& al. (1990) \\
Mesoscale Analysis and Predictions System/Rapid & Bleck \& Benjamin (1993), Benjamin et al. (1998) \\
Update Cycle (MAPS/RUC) Model & \\
Navy Operational Global Atmospheric Prediction & Rosmond (1992), Hogan \& Brody (1993), \\
Systems (NOGAPS) & Staudenmaier (1997d) \\
Mesoscale Model - Fifth Generation (MM5) & Anthes \& Warner (1978), Dudhia et al. (1999) \\
Regional Atmospheric Modeling System (RAMS) & Pielke (1985), Pielke et al. (1992), Cotton et al. \\
Global Environmental Multiscale (GEM) model & (1994, 1995) \\
United Kingdom Meteorological (UKMET) Model & Côté et al. (1998) \\
European Centre for Medium Range Weather Forecasts & Cullen (1993) \\
(ECMWF) Model & Woods (1997) \\
\hline
\end{tabular}




\section{CLIMATE FORECASTS}

\subsection{Forecast products and providers}

Compared to weather forecasts, there were fewer climate forecasts available and fewer providers during this survey (Table 3). Climate forecasts made statements about average or cumulative conditions, rather than specific events, anticipated to occur over an extended period of time.

The CPC produced the official US governmental climate forecasts. Although originally distributed as bulletins (e.g. CPC 1997), during the survey period the climate forecasts were issued only via the Web. The product consisted of a suite of forecasts, issued monthly; they included one 1 mo outlook and a series of 133 mo outlooks each offset by 1 mo. For any single outlook, the CPC provided: (1) maps of surface air temperature and precipitation probability anomalies; (2) a legend describing appropriate interpretation of the probability anomaly maps; (3) a text discussion; (4) maps and tables of historic climatology and probability class limits; and (5) skill maps for some forecast techniques. The climate outlook maps showed likelihoods of occurrence, expressed as probability anomalies, for average air temperature or total precipitation over the period to fall within tercile categories defined by the upper, middle, or lower third of conditions reflected in the historic record from 1961-1990. The maps almost exclusively indicated increased expectations for conditions to fall in the outer categories. The legend indicated that forecasters had an option to increase the expectation for conditions to fall within the central tercile. For that case, the legend decreased expectations for the outer categories (maximum $5 \%$ each), but due to a typographical error did not increase expectations for the central category. When forecasters specified an anomalous probability for a region, there was an implicit statement that the techniques used to create that outlook had some record of skill for that region for that forecast period. In contrast, a 'climatology' designation could mean several forecast techniques disagreed about possible conditions over the forecast period or that no forecast techniques had shown skill for that region and season.

It was common for other organizations, including the media and governmental agencies, to link to or collect and reformat the CPC climate outlooks. However, some organizations provided only portions of the entire CPC product (e.g. outlook maps, without text discussions or even a legend). Some WFOs and the WRCC converted CPC climate outlooks into specialized products (e.g. expected number of rainy days). Groups that had established close relationships with some WFOs received special climate forecasts without cost, while the WRCC provided their products on a subscription basis.

The International Research Institute (IRI) for Climate Prediction produced climate forecasts similar, but not directly comparable, to the CPC official outlooks. IRI forecasts covered only non-overlapping 3 mo seasons, but extended into Mexico rather than stopping at the US border. IRI forecast maps specified precise probabilities (percentages rather than probability anomaly

Table 3. Providers and characteristics of climate forecasts available with Southwest US coverage, April 1998 to March 2000. NWS: National Weather Service

\section{Forecast producers and providers}

\section{Government agencies}

Climate Prediction Center/NWS

NWS Weather Forecast Offices

Goddard Institute for Space Studies/NASA

Government-academic partnerships

Western Regional Climate Center (WRCC)

International Research Institute for Climate Prediction

Experimental Climate Prediction Center

\section{Commercial entities ${ }^{a}$}

Salt River Project (SRP) ${ }^{\mathrm{b}}$

AccuWeather

Fox Weather

Advanced Forecasting Corporation

Environmental Dynamics Research, Inc.

The Old Farmer's Almanac

${ }^{a}$ Inclusion does not imply endorsement of vendor services or products

${ }^{\mathrm{b}} \mathrm{SRP}$ has public and private components

\section{Forecast product characteristics}

\section{Products}

Monthly climate outlooks

3 mo seasonal climate outlooks

Customized conversions of climate outlooks

Lead times

$0.5 \mathrm{mo}$

0.5 to $13 \mathrm{mo}$

0.5 to $18 \mathrm{mo}$

Variables

Average temperature

Total precipitation

Heating and cooling degree days

Custom variables (e.g. number of rainy days) 
ranges) of conditions falling within tercile categories, and the legend was integrated into each map. IRI maps of tercile boundaries indicated they were based on conditions during 1950-1995, not 1961-1990. IRI specified that the 'climatology' designation meant forecasters had no basis for departing from historically based probability distributions. IRI maps also masked out, and provided no forecast for, regions typically receiving less than $15 \%$ of their annual total precipitation during that season. IRI forecasts showed uniform probabilities across large regions, rather than contours centered on subregions with the highest anomalies. Additional maps for the first 3 mo season showed probabilities for conditions to fall within the top or bottom 15th percentile of historic records. Finally, only registered users could obtain the Web-based forecast products, although several months after the forecast season had passed, the products became accessible by all. While a disclaimer stated that IRI forecasts were intended only for research purposes, they had been used in applications (Office of Global Programs 1999) and products were sometimes labeled 'official'.

CPC also produced experimental probability of exceedance forecasts that contained much more information than their official outlooks. The experimental products consisted of a series of 102 graphs, with each series corresponding to a probability anomaly map of the official outlook and each graph representing a subregion within the US (Barnston et al. 2000). The graphs expressed the climate forecasts using continuous distributions of the probability that temperatures or precipitation quantities would be exceeded. They also showed historic observations, the associated climatologic distribution, recent observations, an envelope of uncertainty about the forecast distribution, and text commentary that highlighted forecast attributes.

Both the Experimental Climate Prediction Center and the Goddard Institute for Space Studies generated forecasts, not for decision making, but in order to test dynamic numerical models they were developing or extending. However, the forecasts were publicly accessible on the organizations' Web sites and sometimes labeled 'official' by the Experimental Climate Prediction Center. The organizations' forecasts encompassed many more variables (e.g. wind speed, relative humidity, soil moisture) than official NWS products and were expressed as quantities, not probabilities.

SRP generated climate forecasts primarily for internal use to support planning for their water resources and power operations. Other commercial producers of climate forecasts were clearly targeting external commercial interests, including the financial and insurance industries. Some vendors provided products similar to official CPC outlooks (e.g. AccuWeather, Fox Weather). Others offered forecasts with longer lead times (e.g. 18 mo from Advanced Forecasting) or specialty variables (e.g. degree-day outlooks from Environmental Research Dynamics). Many commercial products, standard or customized, were expressed as quantities, not probabilities.

\subsection{Forecast techniques}

Compared to weather forecasts, the climate forecasts encountered in this study were produced from a wider variety of techniques (Table 4) that included both statistical and conceptual modeling approaches. CPC and IRI forecasts were created by subjectively combining results from several techniques and sometimes making adjustments based on current observations, recent research, and expert judgement. Others (e.g. Experimental Climate Prediction Center, Goddard Institute for Space Studies) were based on unadjusted output from their numerical models. Techniques for producing commercial products were proprietary and not described for the general public.

CPC's roster of statistically based forecast techniques was typical of those used by other groups. A form of multivariate linear regression, canonical correlation analysis, attempted to represent slowly evolving effects of ocean conditions on the atmosphere, such as the El Niño-Southern Oscillation (ENSO) and the North Atlantic Oscillation. The technique predicted spatial patterns of temperature and precipitation anomalies based on spatial anomalies of global sea-surface temperatures (SSTs), atmospheric pressure heights, and continentalscale temperature and precipitation. Screen multiple linear regression was similar to canonical correlation analysis, but provided only localized forecasts; it was used where significant geographic features (e.g. mountains, coastlines) caused climate to be largely controlled by only a few ocean or atmospheric conditions. The optimal climate normal technique subtracted climatologic averages (e.g. 1961-1990) from averages of the past $10 \mathrm{yr}$ for temperature and $15 \mathrm{yr}$ for precipitation, although other periods could be more optimal for some regions. The technique accounted for interannual persistence of conditions within interdecadal climate regimes or long-term trends, but was apt to fail during periods of regime transition. The soil-moisture tool used prior soil-moisture conditions and temperature anomalies to account for intraseasonal effects of soil moisture on regional surface climatology. Composite analysis and constructed analogs relied on similar conditions from the historic record (e.g. years with the same ENSO state) to suggest potential future conditions.

The CPC typically made less use of outputs from global climate models (GCMs) than other climate forecast providers. The GCMs attempted to consider the 
Table 4. Techniques used to produce climate forecasts, April 1998 to March 2000

\begin{tabular}{|c|c|}
\hline Technique name and acronym & Sources \\
\hline \multicolumn{2}{|l|}{ Climate Prediction Center (CPC) } \\
\hline Canonical Correlation Analysis (CCA) & Barnston (1994), Barnston \& Smith (1996) \\
\hline Screen Multiple Linear Regression (SMLR) & Unger $(1996 a, b)$ \\
\hline Optimal Climate Normals (OCN) & Huang et al. (1996a) \\
\hline Soil Moisture Tool & CPC (1995), Huang et al. (1996b) \\
\hline Constructed Analogs (CA) & СРC (1995) \\
\hline Composite Analysis (CA) & Higgins \& Mo (1997), CPC (2000) \\
\hline Coupled Model Prediction (CMP) & Ji et al. (1994a,b), Livezey et al. (1996), Barnston (1998) \\
\hline \multicolumn{2}{|l|}{ International Research Institute } \\
\hline Climate Community Model (CCM3) & Kiehl et al. $(1996,1998)$ \\
\hline European Community Hamburg (ECHAM) Model & Bengtsson et al. (1993), Barnett et al. (1994) \\
\hline Medium Range Forecast (MRF) Model & National Meteorological Center (1988), Kalnay et al. (1990) \\
\hline Statistical analyses & Goddard et al. (2000) \\
\hline \multicolumn{2}{|l|}{ Experimental Climate Prediction Center } \\
\hline Global Spectral Model (GSM) & Kalnay et al. (1996), Roads et al. (1999) \\
\hline Regional Spectral Model (RSM) & Juang \& Kanamitsu (1994), Juang et al. (1997), Chen et al. (1999) \\
\hline Mesoscale Spectral Model (MSM) & Juang $(2000)$ \\
\hline Oberhuber Global Isopycnic Ocean Model & Oberhuber (1993) \\
\hline Hybrid Climate Model (HCM) & Pierce (1996) \\
\hline $\begin{array}{l}\text { Goddard Institute for Space Studies } \\
\text { SI97 }\end{array}$ & Wilder et al. (1997), Borenstein et al. (1998) \\
\hline \multicolumn{2}{|l|}{ Salt River Project } \\
\hline Entropy Model & SRP (1998) \\
\hline \multicolumn{2}{|l|}{ Old Farmer's Almanac } \\
\hline Astronomical model & Yankee Publishing (2000) \\
\hline
\end{tabular}

myriad physical processes that affect climate, including the mutual influence between the oceans and atmosphere. However, some GCMs contained more detail about slowly evolving ocean-atmosphere interactions (e.g. heat transfer), while others had more detail about rapidly changing atmospheric conditions (e.g. deep cumulus convection). Typically, 1 or several GCMs that coupled ocean and atmospheric behavior were used with recent observations and slight variations thereof to forecast several possible SSTs. The forecasted SSTs and their slight variations were then used as multiple starting conditions for GCMs that focused more exclusively on atmospheric processes. Each model run comprised 1 member in an ensemble of forecasts produced by a GCM. Details of the specific variables used, variations in starting conditions, number of model runs, and model run lengths were highly variable and often difficult to explicitly determine from available documentation.

\section{HYDROLOGIC FORECASTS}

\subsection{Forecast products and providers}

Relatively few entities were involved in producing hydrologic forecasts (Table 5), although collectively the products covered time scales spanning the equivalent of both weather and climate forecasts. As with weather and climate forecasts, the NWS provided the official government hydrologic forecasts. WFOs were responsible for issuing flood and flash flood watches and warnings for their service areas, but relied on coordinated consultation with NWS River Forecast Centers (RFCs) and local emergency management agencies (e.g. flood control districts); 4 RFCs provided coverage for watersheds in the Southwest. Depending on the specific product, flood forecasts had lead times ranging from minutes to several hours and areal coverage ranging from single stream locations to multiple counties. They generally provided qualitative statements about the potential for extreme conditions, without quantifying streamflows, water levels, or probabilities of occurrence. Flood statements were used to terminate watches or warnings. Quantitative guidance products (e.g. headwater flash flood guidance, threshold runoff) were generated by the RFCs and WFOs, primarily for internal use. However, at least some WFOs also shared the products with local emergency management agencies. Also generated and issued by WFOs, flood potential outlooks provided text-based descriptions of the potential for water levels to cause damage to property, but over the next several weeks. 
QPFs were created by the NWS Hydrometeorological Prediction Center (HPC) and local WFOs, primarily as guidance for use in generating other products. HPC QPFs were publicly available on their Web site, but were not official products intended for public use. They consisted of national maps showing anticipated depths of rainfall in 6 or $24 \mathrm{~h}$ increments over the next 1 or $2 \mathrm{~d}$, snow depths, or up to 4 kinds of excessive rainfall potential, all without probabilities.

A variety of daily stage (water level) or discharge forecasts were made by the RFCs and then issued, without modification, by the WFOs. Although given a variety of names, the products often contained similar kinds of information, ranging from qualitative descriptions of current or anticipated conditions to reviews of recent and historic conditions to quantitative stage or discharge predictions without accompanying probabilities. They were typically issued with 1 to $5 \mathrm{~d}$ lead times, although there was variation in temporal coverage depending on location. The CBRFC also had experimental probabilistic discharge forecasts for some Col- orado watersheds available for public access on their Web site, although in forms (e.g. long tables of model output values) that would discourage untrained users.

Historically, snowmelt peak flow forecasts and water supply outlooks were issued by the RFCs in monthly bulletins (e.g. CBRFC 1992, 1998). However, during the survey period, the products were increasingly available through RFC Web sites and WFO delivery mechanisms. In the Southwest, peak flow forecasts were issued for March-June and March-April for the upper and lower Colorado River basins, respectively. They predicted maximum mean daily flows expected to occur, from melt of the past winter's accumulated snow pack, sometime during the snowmelt season (March-May for Arizona and April-July for most other locations). The forecasts were expressed as flow rates with 5 levels of probability $(90,75,50,25$, and $10 \%$ exceedance quantiles). They were also accompanied by historic maximum peak flows, average peak flows, flood flows (at which damages would begin), and the normal timing of peak flow occurrence.

Table 5. Hydrologic forecasts available with Southwest US coverage, April 1998 to March 2000. NOAA: National Oceanic and Atmospheric Administration

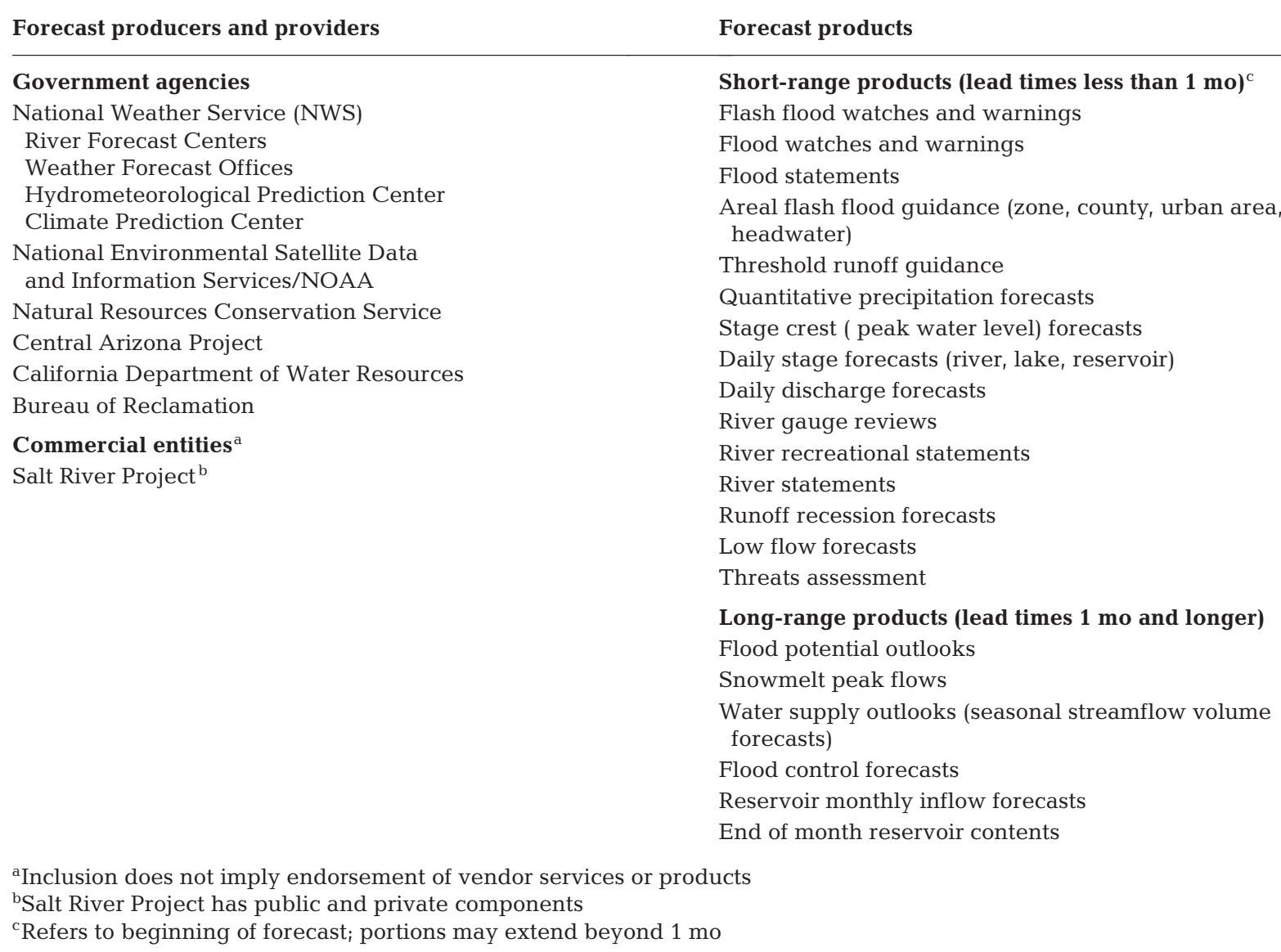


Water supply outlooks were unique in that they reflected the absence of water-management influences (termed 'naturalized' flows); other hydrologic forecasts considered at least some aspects of current water diversions or reservoir regulations. Water supply outlooks were issued biweekly, January-June and January-April for the upper and lower Colorado River basins, respectively, but sometimes earlier with early snow accumulation. They had varying temporal coverage reflecting basin seasonal flow characteristics (e.g. January-May for the Gila River, April-July for the San Juan River) and became shorter as the forecast season progressed. Water supplies were expressed as 'reasonable minimum', 'most probable', and 'reasonable maximum' seasonal total water volumes, respectively, corresponding to 90,50 , and $10 \%$ exceedance probabilities. They were compared to 1961-1990 median volumes and disaggregated into monthly forecast volumes as well. CBRFC graphical products showed forecast flow volumes relative to climatological median volumes, with no probabilities, while other RFCs used alternative formats. The CBRFC also generated alternative experimental water supply outlooks, based on newer methods, but only for internal evaluation.

Concurrently issued forecasts of flood control, reservoir monthly inflows, and end-of-month reservoir contents were all variants of the water supply forecasts. Generally, they included more water-management influences and were expressed only as quantities (e.g. percent of 1961-1990 median flows, percent reservoir capacity), without probabilities. The CBRFC also produced extended exceedance probability water supply outlooks, covering up to $2 \mathrm{yr}$, for the Bureau of Reclamation's use in regulating reservoirs along the Colorado River and its tributaries.

The NRCS also issued water supply outlooks for the Southwest, in coordination with the CBRFC and SRP. Their official forecast values were identical to CBRFC values, but included 70 and $30 \%$ exceedance quantiles as well. NRCS also produced lake and reservoir stage forecasts, peak-flow forecasts, runoff recession, and low-flow forecasts, with varied temporal coverage and lead times, for specific clients under special arrangements. NRCS products were issued via bulletins (e.g. Soil Conservation Service and NWS 1994), their Web site, the NRCS Centralized Forecast System, and direct communication with clients.

SRP, the Central Arizona Project, and the California Department of Water Resources produced water supply outlooks for managing their own water projects. SRP also produced QPFs for late-summer tropical storms and during winter, as well as forecasts of snowaccumulation elevations throughout the winter. SRP QPF forecasts covered 6 to $24 \mathrm{~h}$ periods with lead times extending to $10 \mathrm{~d}$. SRP products were available only for internal operations, with the exception of the water supply outlooks for the Salt and Verde rivers, which were provided to the CBRFC and NRCS for producing official coordinated forecasts.

During this survey, the NOAA National Environmental Satellite Data and Information Service had a publicly accessible experimental flash flood Web site. It provided recent satellite-based estimates of rain rates, atmospheric precipitable water, and soil wetness on which to base forecasts of flash-flood potential. It also provided tutorials on making flood forecasts, targeted at potential users (e.g. canoe livery owners).

Finally, even though many universities and research groups were involved in developing new hydrologic models and forecasting tools during the survey period, none were found that provided operational forecast products. In fact, few groups other than those mentioned referred to hydrologic forecasts at all. One exception was the Bureau of Reclamation, which provided QPFs, obtained from NWS sources, through their subscription-based AWARDS system and freely accessible Rivers and Meteorology Group Web site. However, they did not provide other hydrologic forecasts.

\subsection{Forecast techniques}

Hydrologic forecasts were made using a variety of techniques (Table 6). Short-range hydrologic forecasts involved intensive coordination between WFOs, RFCs, and even local emergency management agencies. Like weather forecasts, QPFs were generated by subjectively combining outputs from multiple numerical weather models, climatology, and forecaster experience. QPFs from WFOs were generally relied upon the most, by both WFOs and RFCs. Flash-flood forecasts often were based on real-time monitoring of watershed conditions, while flood forecasts were also based on unit hydrographs driven by real-time precipitation observations, tempered by expert judgement and guidance products. Guidance products were based on continuous accounting of soil moisture and snow cover, generally using the same procedures as for daily stage and discharge products. They were generated using the NWS River Forecast System (NWSRFS), a complex software system comprised of over 400000 lines of code. At the heart of this system were models for snow accumulation and ablation, rainfall-runoff relationships, and routing of flows down river channels. All of the models were developed more than 30 yr ago, although upgrades have occurred more recently. The most common approach was to use the NWSRFS deterministically, using a single series of inputs (e.g. from a QPF) to produce a single forecast. Experimental probabilistic forecasts generated by some RFCs (including experimental water supply outlooks) forced the sys- 
Table 6. Techniques used to produce hydrologic forecasts, April 1998 to March 2000

\begin{tabular}{|ll|}
\hline Technique name and acronym & Sources \\
\hline Numerical weather models $^{\mathrm{a}}$ & See Table 2 \\
Balling precipitation model $^{\mathrm{a}}$ & SRP (1998) \\
Observing systems & \\
Unit hydrographs & Maidment (1993) \\
Curve number method & Soil Conservation Service (1985, 1986) \\
National Weather Service River Forecast System & Office of Hydrology (1996), Hydrologic \\
(NWSRFS) & Research Laboratory (1998) \\
Snow accumulation and ablation model (SNOW-17) & Anderson (1973) \\
Antecedent Precipitation Index (API) models & Kohler \& Linsley (1951), Nemec \& Sittner (1982) \\
Sacramento Soil Moisture Accounting (SAC- & Burnash et al. (1973), Burnash (1995) \\
SMA) model & \\
Lag and k flow routing models & Linsley et al. (1975) \\
Ensemble streamflow prediction (ESP) & Day (1985) \\
Multivariate linear regression & CBRFC (1992), Garen (1992) \\
aFor quantitative precipitation forecasts & \\
\hline
\end{tabular}

tem with multiple inputs selected from historic meteorologic records, termed ensemble streamflow prediction (ESP). The California Department of Water Resources also used ESP for their forecasts, with the Sacramento Soil Moisture Accounting (SAC-SMA) model as the kernel.

Both the CBRFC and NRCS based their long-range forecasts on multivariate regression relationships rather than dynamic models. Unique regressions for each forecast period and location used subsets of monthly or seasonal observations of precipitation, streamflow, ground-based snow-water depths, and routed forecasted streamflows. The regression equations produced only a single deterministic water supply volume representing the $50 \%$ exceedance forecast. Forecast volumes for additional exceedance quantiles were obtained by overlaying a normalized error distribution, determined during equation fitting, centered on the deterministic regression forecast. Regression equations for some Arizona locations incorporated Southern Oscillation Index values, allowing their water supply outlooks to reflect climatic teleconnections. NRCS used curve-linear equations with variables decorrelated using principal component analysis. CBRFC forecasters selected one of several linear regression equations, some of which used transformed variables. Additional statistical analyses were used to disaggregate seasonal outlooks into monthly volumes. SRP used regression models as well as techniques based on curve numbers and input from their climate model. After the CBRFC, NRCS, and SRP made their independent water supply forecasts, they relied on their expert judgment to subjectively coordinate forecasts into a final official product with identical values.

\section{DISCUSSION}

In reviewing the forecasts encountered in this survey, several issues became apparent that relate to forecast producers or potential users. Critique of individual forecast techniques is beyond the scope of this survey. The point is not to judge one model to be better than another or to disparage forecasting efforts. Rather, this discussion is intended to initiate a dialogue about the process of developing and providing forecasts, including how forecasts can be made accessible to a variety of potential users in ways that improve the ease, accuracy, and reliability of interpretation and application. Some topics concern dilemmas that lack a clear way forward.

\subsection{The forecast milieu}

During this survey, potential users of hydrometeorologic forecasts faced myriad products issued by a complex mix of governmental agencies, universities, private enterprises, and other organizations. Forecasts were issued via a complex mix of media as well, including published reports, newspaper, radio, and, increasingly, computers. The sheer variety of forecast products and sources poses the potential to limit the credibility of any single forecast. A user might well question why slightly different forecasts are distributed by different entities or, when forecasts are quite different, wonder which is more reliable. As Pagano et al. (1999) found, users can become overwhelmed by the many choices available and then settle for the forecast easiest to access, rather than the best to use. 
In addition, the state of forecasting was constantly evolving. New products were generated and standard products were communicated in new ways, on an everchanging trajectory. Easily available Internet access radically changed the means for obtaining forecast products. Many products and ancillary information (e.g. technique descriptions, input data) were delivered primarily, if not exclusively, via the Web. The most efficient approach for learning about available NWS forecasts was by contacting WFO staff, who also assisted in product interpretation. Pagano et al. (1999) found that users who had ongoing relationships with WFOs had the best understanding of forecasts related to the 1997-1998 El Niño event.

\subsection{Official, operational, experimental, and research forecasts}

In practice, there appeared to be little distinction among official, operational, experimental, and research forecasts. However, clear identification has practical importance because users now have direct access to all forecast types. Operational products are routinely produced by an agency, using established procedures that have undergone extensive review. There was some disagreement about whether official forecasts included any publicly available operational product of the NWS, the official forecasting agency, or only some subset required by NWS legal mandates or internal criteria. NWS documentation did not identify whether products were discretionary or mandatory. The NWS did, however, distinguish among official channels for providing products; NOAA Weather Radio was an official source for weather forecasts; the Internet was not. Experimental products have not yet received official sanction, although they may be generated in an operational setting for an extended period of time to test whether they warrant transition to higher status. Research products are at even earlier stages of development. However, some were posted on the Web, in forms that looked like operational forecasts, as a means of sharing results and demonstrating conversion of research into useable products.

Should only NWS forecasts be labeled official? There was clearly potential for confusion when non-NWS providers labeled some of their climate forecasts 'official', but the NWS does not have exclusive rights to the term (Kerr 1990). What responsibilities do research groups have when making their forecasts publicly accessible? Research forecasts may appear attractive to users because they provide higher resolution, longer lead times, or precise quantities rather than probabilities, but fundamentally they are more speculative than products that have advanced to operational or official status.

\subsection{Documentation}

Documentation about the forecasts encountered in this survey varied greatly in quality and availability to users. Inevitably, ancillary information on the Web more accurately reflected current interpretations and techniques than published literature, because electronic texts had been periodically updated. Discussions accompanying NWS area weather forecasts and CPC climate outlooks were unique in describing details about the production of individual forecasts. For most other products, those details were simply unavailable. The absence of documentation, describing how expert judgment was incorporated into the forecasts or what conditions were used to initialize models, limits opportunities to improve products through retrospective analyses of forecast processes.

Clear documentation about hydrologic forecasts was particularly difficult to obtain without going directly to the forecasters. It appeared that descriptions of NWS hydrologic forecasting operations focused almost exclusively on plans for the future rather than actual practices, in order to garner support for a hydrologic modernization initiative analogous to that for meteorologic operations. In some cases the documentation was inconsistent and out-dated, posing difficulty in distinguishing between modernization plans and what procedures were really used at various localities.

\subsection{Forecast interpretation}

Every advanced forecast represents a tremendous investment: in observation systems, computational capabilities, physical process research, and professional training. However, even the best forecasts can be worthless if users misinterpret them. Text-based forecasts used terms with specific meaning for forecasters (e.g. Branick 1996) but without intuitive interpretation by users (van Bussem 1999). Relative magnitudes of numerical values, including probabilities, can be reliably interpreted, but confusion often exists about the meaning of forecast variables associated with the probabilities (van Bussem 1999).

In particular, proper interpretation of the probability of precipitation forecasts engendered extensive debate. Technically, the forecasts indicate the chance of precipitation occurring at any single point within a forecast area (NWS 1995). The probability can be determined by assigning the value for a single point (e.g. the local airport) throughout the forecast area or by averaging the probabilities for several points (e.g. rain-gauge locations) within a forecast area. WFO forecasters also described the forecast as the expected areal coverage of precipitation within the forecast 
area. However, the 2 definitions are equivalent only when averaged over many events (Schaefer \& Livingston 1990). During the peak of the summer monsoon season, areal coverage interpretations are appropriate because storms are likely to occur somewhere within the forecast area. In contrast, winter forecasts are more appropriately considered an average probability because winter storms have broad areal extent; an areal coverage interpretation would require rarely used high forecast values (e.g. 70\%). NWS precipitation forecasts did not identify the intended interpretation. Further, neither interpretation is consistent with what most people think, including many meteorologists (van Bussem 1999), who interpret it as the chance of precipitation occurring somewhere in the forecast area.

Probabilistic climate outlooks were also often misunderstood, both by researchers and users. The concentric contours and probability anomalies in CPC forecasts appeared to be more confusing than the uniform regions and explicit probability distributions of the IRI forecasts. The climatology designation was especially misleading in suggesting that forecasters attributed equal likelihood to all conditions, when they actually meant forecast uncertainty was so great that likelihoods were unknown and no forecast was possible. The climate forecasts also offered a limited perspective, with probability anomalies expressed relative only to a subset of historic records (e.g. 1961-1990 for CPC forecasts). With understanding of decadal- and centennial-scale climate regimes improving, neglecting to communicate more extensive historic information seems ill advised, especially for decisions sensitive to extreme conditions or with long-lasting consequences.

Seasonal water supply forecasts posed a range of interpretive problems. First, as 'naturalized' flows, they required users to adjust projected runoff volumes for anticipated diversions and reservoir regulations. The adjustments could be complex (CBRFC undated) and significant (e.g. 34 adjustments for the Colorado River near Cisco, Utah, that cumulatively reduced naturalized flows by $30 \%$ ), yet incomplete in representing all human impacts. Further, adjustments were based on typical management decisions that would be unrealistic during extreme conditions. Second, for rivers with skewed flows, declaring the deterministic forecast value 'most probable' conveyed a false sense that it had higher probability than any other value. While expected values, statistically, are the most probable, medians represent only the midpoint of a distribution; they are expected to be too high one-half the time and too low the other half. Third, calling the 10 and $90 \%$ exceedance forecasts 'reasonable' maximums and minimums conveyed a false sense of their appropriate- ness for decision making. Reasonableness depends on decision makers' risk tolerance and loss functions unique to each situation. Further, interpretation of the exceedance quantiles was problematic because the quantiles were based on a normal distribution of regression error, shifted so the coordinated forecast represented the mean of the error distribution. The error generally remained constant from year to year, neglecting variations in uncertainty based on forecast magnitudes. Alternatively, ESP procedures provide probabilistic forecasts that better reflect total forecast uncertainty, because they incorporate non-linear impacts of meteorologic variability as well as unavoidable model errors.

\subsection{Forecasting flexibility}

The state of meteorologic forecasting can be characterized by rapid incorporation of research findings and products. New forecast techniques moved relatively quickly from research to experimental to operational status. Experimental products were routinely made available to forecasters, and operational forecasts were adjusted based on recent diagnoses and improved understanding of ocean and atmospheric dynamics and linkages. The meteorologic forecasting situation resulted from a distinct shift in NWS institutional philosophy (Mittelstadt 1997). Previously, NWS forecasting models were limited to those passing development and evaluation thresholds; they were used unchanged until major scientific and technological advancements were incorporated and evaluated. Subsequently, however, model changes were incorporated as soon as they passed initial testing and operational adjustments (e.g. data handling) could be made.

In addition, because meteorologic forecasters had broad flexibility in generating their products, they could combine results from many different NWS units, each of which maintained responsibility for their own models, as well as forecasts generated by non-NWS groups. Forecasters had flexibility to give varying precedence to different forecast techniques in different regions, during different seasons, and for unusual conditions.

In contrast, the state of hydrologic forecasting can be characterized by relatively slow evolution, with constraints imposed by complex legacy ${ }^{1}$ data management systems, longstanding standard operating procedures, and an institutional preference for uniformity in opera-

\footnotetext{
${ }^{1}$ Legacy systems neglect modern computer capabilities in order to maintain consistency with procedures developed with now-abandoned computer architectures
} 
tions. During the survey period, the NWS had a strong commitment to only 2 conceptual hydrologic models (the Antecedent Precipitation Index and SAC-SMA). Forecast-improvement efforts focused primarily on improved data access and displays, approaches for implementing ESP, and statistical analyses of model outputs, rather than upgrading conceptual models. The institutional philosophy was that new models were required to fit within the existing data-management infrastructure and demonstrate improved performance in an independent operational setting over several years. Those requirements frustrated members of the hydrologic research community who had developed new models or diagnoses that they thought should be incorporated into operational forecasts, but who had not developed operational systems parallel to those of NWS.

NWS hydrologic forecasters were also limited to using the NWSRFS and not using external forecasting tools, with 2 significant exceptions. First, WFO forecasters relied on a high degree of coordination with RFCs and even local flood control districts in their issuance of flood warnings and watches. Second, RFC forecasters cooperated with the NRCS and SRP in producing seasonal water supply outlooks, with each group adjusting their independent forecasts to create a unified product. These relationships represent precedents for more efficient incorporation of new models and data into official forecasts. However, the hydrologic research community would need to commit to producing their own operational hydrologic forecasts.

\subsection{Forecast performance}

The meteorologic community has a long history of evaluating forecasts (Clayton 1889 is an early example), but readily available information about the quality of actual weather forecasts is still rare beyond reviews of specific events (Brooks et al. 1997). Detailed evaluations of weather forecasts have not typically focused on the Southwest, but instead have included the region in larger analyses for the Interior West and Central or Southern Rocky Mountains. NWS forecast groups agreed that better verification of forecast performance was needed, especially at local scales (HPC 1997, Junker 1998). Conditions in the Southwest, however, make forecast assessment difficult. Sparse data networks and spatial heterogeneity of meteorologic conditions can make a mockery of claims for high confidence in 'observed' values. Comparison of individual forecast techniques is complicated by differences among model formulations. For example, because each model used unique terrain descriptions that could be vastly different, forecasted temperatures referred to different locations and elevations. Finally, constantly evolving model formulations suggest that evaluations can become outdated quickly.

Climate-forecast evaluations have periodically appeared in the scientific literature (Bettge et al. 1981, Priesendorfer \& Mobley 1984, Livezey 1990, Murphy \& Huang 1991, Livezey et al. 1997). However, with some exceptions (e.g. Lehman 1987, Mjelde et al. 1993) the evaluations were framed for researchers and forecasters rather than users, and did not distinguish among regions within the Southwest; others supported internal operations and were not broadly distributed (e.g. SRP 1998). CPC outlooks posted on the Web included maps of skill for some forecast techniques, but they were cryptic, offered no interpretive information, and reviewed what constituted only partial input to final forecasts. The latter limitation exists for any evaluation focused only on a single technique (e.g. Unger 1996a,b, Peng et al. 2000). CPC also provided quantitative evaluations of each official forecast on their Web site, but results reflected conditions across the entire conterminous US, without regional breakdowns. Reviews of overall climate outlook performance designed for the general public (CPC 1995, WRCC 1998) described elements of expected performance in the Southwest, but lacked quantitative assessments. Goddard et al. (2000) reviewed climate-forecasting capabilities, although the techniques were not associated with specific forecast providers or products. Other evaluations addressed forecast performance only for short periods, e.g. during the 1997-98 El Niño event (Leetma 1998, Barnston et al. 1999, Mason et al. 1999, Office of Global Programs 1999, Pagano et al. 1999).

As long-term forecasts, climate outlooks pose special difficulties for quantitative evaluation. First, climate outlooks concern only average temperatures and total precipitation over an entire forecast period. They say nothing about daily, weekly, or even monthly extremes within a 3 mo forecast period or whether precipitation will occur as many small or a few large events. However, in the semi-arid Southwest, seasonal precipitation can be defined by a single event, such as Hurricane Nora in 1997 (Pagano et al. 1999). Second, limited samples compromise even the most mathematically rigorous analyses. Spatial and temporal autocorrelation reduces effective sample sizes further, while forecast technology changes faster than sufficient data can accumulate.

The hydrologic community does not have a strong tradition of evaluating operational forecasts. Workshop participants recalled failed efforts in the late 1970 s to compare operational performance of hydrologic models and forecasts. Conflict arose over which basins, data sets, evaluation periods, and techniques to use. 
The overall sense was that hydrologists and their institutions had too much at stake, professionally and financially, to risk the possibility of their techniques being proven inferior to others in a head-to-head comparison. Thus, most evaluations have focused on alternative techniques (e.g. McCuen et al. 1979), not operational products.

Seasonal water supply outlooks inherently provide some evaluation information, through the various exceedance quantiles, because they are based on the standard error of regression calibration. In addition, the CBRFC and NRCS provided annual reviews of the past season's outlooks and actual conditions (e.g. CBRFC 1991), although without addressing performance over more extended periods. The most recent evaluation of operational hydrologic forecasts dealt with seasonal outlooks issued through 1980 (Shafer \& Huddleston 1984), using simple statistics (e.g. error and bias) and treating the $50 \%$ exceedance forecasts as deterministic, not probabilistic, values. NWS has developed procedures for evaluating experimental ESP forecasts (Perica 1998), but no assessments had been completed for Southwest watersheds during the survey period. Comprehensive evaluations of historic hydrologic forecasts are limited by lack of computerized data and documentation of model details (e.g. changes in the regression equations). For seasonalscale forecasts, potential assessments are also limited by small effective sample sizes, because few outlooks are issued each year and there is high correlation among conditions within a season.

\subsection{The future of forecasting}

The evolution of computer power and remote sensing of oceanic, atmospheric, and land conditions have produced significant shifts in the philosophy and practice of weather and climate forecasting, although not yet for hydrologic forecasting. The meteorologic forecasting community incorporated spatially variable approaches to dynamic conceptual modeling, while conceptual hydrologic models were still lumped applications, treating large regions as a single homogeneous unit. While the availability of geographic information systems, digital models of terrain characteristics, and satellite remote sensing fostered substantial research to develop distributed hydrologic models, the models were far from being used operationally.

Research focused on interactions among oceanic, atmospheric, and land systems has resulted in the incorporation of limited coupling into operational forecasts. In particular, SSTs over the Pacific Ocean were used in several GCMs to affect climate forecasts over continental areas, and ENSO phenomena were incor- porated into some statistical equations forecasting water supply in the Southwest. However, other largescale phenomena (e.g. Pacific North American and Southwest trough circulation patterns and the Pacific Decadal Oscillation), while recognized as having important consequences for Southwest hydroclimatology (Cayan \& Peterson 1989, Redmond \& Koch 1991, Cayan 1996, Woodhouse 1997), were incorporated into operational forecasts in very limited ways or not at all.

Some nested models were being used for weather forecasts, but many alternative implementations remained to be explored (e.g. using 1-way or 2-way feedbacks between nested models or nesting with more than 2 tiers of models). Nesting of models with different spatial coverage and resolution is wrought with complexities related to appropriate linkages of processes and other issues. In contrast, temporal nesting is conceptually straightforward, but was largely neglected by forecast operations during the survey period. While operational forecasts were made for time scales ranging from minutes to several months, there were no explicit connections between them. Further, while forecasters generally recognized that the accumulation of short-term forecasts should be consistent with longer-term forecasts, both production and evaluation of forecasts generally neglected nested time intervals.

A reasonable vision of forecasting over the extended future is for increasing complexity and interconnectivity of all phases of modeling. A forecast system of the future might be expected to include incorporation of a greater variety of data; coupling between oceanic, atmospheric, and hydrologic processes; nesting across multiple spatial and temporal scales; and updating of forecasts by assimilation of recent observational data. Further, the future of forecasting is likely to include a larger number of techniques, both statistical and dynamical, empirical and conceptual. The best means for integrating and communicating diverse forecasts will likely become an increasingly important issue for both forecasters and forecast users.

Large research programs, with joint participation by many research groups, are focused on developing the next generation of forecast tools. However, based on the slow rate of transition of research into hydrologic operations, it is likely to be many years before the research programs will result in new operational hydrologic forecasts. Theoretically, there are significant opportunities for relatively rapid improvement of operational hydrologic forecasts based on recent improvements in climate-forecast skill. However, because hydrologic research programs are generally devoted to the next generation of forecast tools and exclude current operational techniques, those opportunities have not yet been realized. 


\section{RECOMMENDATIONS}

Review of the weather, climate, and hydrologic forecasts available for the Southwest, along with institutional considerations, suggests a range of opportunities for improving the production, delivery, and use of forecast products. The following recommendations require interdisciplinary collaboration, not just between the physical science research community and operational forecasters, but with current and potential forecast users and social scientists as well.

\subsection{Product content and communication}

Qualitative aspects can be as important as any quantitative attribute in affecting how users interpret, apply, and ultimately judge forecast products (Nicholls 1999). This survey revealed a wide array of methods and formats used to communicate forecasts. Discussions with study participants revealed that even those with technical backgrounds were consistently misinterpreting some products. Surveys, structured discussions, and other innovative approaches (Stern \& Easterling 1999) should be used to comprehensively assess forecast qualities and influence development of products that foster easy, accurate, and reliable interpretation. Among the issues that should be addressed are the following:

- visualization of forecasts, both spatial (e.g. climate outlooks) and temporal (e.g. water supply outlooks);

- communication of probabilistic forecasts in ways that present likelihoods across entire distributions and relative to base probabilities (e.g. IRI climate forecasts and water supply outlooks);

- presentation of ancillary information (e.g. text discussions, historic data, and local climatologic distributions); and

- designation of forecasts as official, operational, experimental, or research products.

Further, while potential users had opportunities to access a variety of products, there was little supporting information to help them choose which products would be most appropriate for their specific needs. Decision makers should be encouraged to establish ongoing relationships with forecast providers, particularly WFOs. The complexity of some products and the diversity of potential users suggest an intermediary role for other organizations as well, as translators and advisors and to develop more useable products. Toward that end, efforts should focus on how specific products are used and establishing priorities for fulfilling users' needs for new products. During the 1997-98 El Niño event, Pagano et al. (1999) assessed decision makers' use of hydroclimatic forecasts in the context of antici- pated water surplus in the Southwest. Needed still, however, are similar studies conducted during La Nina conditions to address slowly developing drought conditions lacking easy action options.

Finally, this 2 yr survey provides only a panoramic snapshot of forecasts available for the Southwest. Since the end of the study period, new forecast products and providers have emerged on the scene, e.g. excessive heat outlooks issued by the CPC. In another case, a private company began selling attractive, but incorrect, reinterpretations of CPC climate outlooks. Additional surveys should be repeated periodically to assess the evolution of forecast products and their delivery.

\subsection{Modeling capabilities}

Large ongoing programs in atmospheric and hydrologic research make clear that current modeling capabilities do not provide sufficient predictive capabilities for many conditions and purposes. In the Southwest, where global- and continental-scale climate processes may sometimes be less significant than regional land surface-atmosphere interactions, regional climate models would be useful for downscaling climate outlooks or increasing the frequency of non-climatology climate forecasts, especially for the summer monsoon season. The modeling recommendation rated highest at the forecast assessment workshop called for more effectively incorporating climate forecasts, and their variable quality, into statistical water supply outlooks. Additionally, studies should evaluate the potential for frequent areal measurements of snow conditions (e.g. from the NWS National Operational Hydrology Remote Sensing Center) to improve hydrologic forecasts using operational statistical and conceptual models.

\subsection{Forecast evaluation}

Organizations that make forecasts publicly available should also provide publicly available evaluations of forecast performance. Assessments of historic forecasts provide users with a quantitative basis for forecast credibility and can demonstrate product improvement over time, enhancing the potential for decision makers to respond appropriately to both anomalies and forecasts of their occurrence (Sarewitz et al. 2000). However, this survey found that forecasts were rarely accompanied by clear quantitative assessments of past performance. Recent evaluations of CPC climate outlooks, completed subsequent to the survey period (Wilks 2000, Hartmann et al. 2002), represent important progress but are not accessible to general users 
when they acquire forecasts. From a user's perspective, a better alternative would be an interactive Web site that allows users to evaluate past forecasts that cover the periods and lead times relevant to their situation, using multiple forecast performance measures that reflect their sensitivity to different forecast qualities.

For operational forecasters, frequently updated evaluations can help in calibrating the uncertainty they attribute to a final product. For the research community, evaluations can identify situations where forecasts have been consistently inaccurate, suggesting unique situations and potential model improvements. Hindcasts, whereby predictions are made of the past in a simulated operational setting, are useful for individual forecast techniques, but less so for products that incorporate forecaster subjectivity. However, hindcasts could effectively assess the objective criteria for assigning climatologic probabilities in the CPC outlooks, as well as hydrologic forecasts made using ESP or statistical regressions.

Finally, forecasters and the research community should jointly establish an archive of operational products and ancillary information. The NWS Surface Records Retention System stores all NWS products issued through their official channels, but it was designed for accessing forecasts related to specific events, has high retrieval costs, and was uniformly seen by NWS personnel as ineffective for extracting hypertemporal records. However, the transient nature of many forecasts and the lack of archived details about their production preclude evaluation across a broad range of products. Without periodically updated evaluations that are accessible to users, the scientific and forecasting communities risk that inevitable failures of specific forecasts will engender persistent skepticism, even as scientific understanding and forecast techniques improve.

Acknowledgements. We appreciate the candor of each individual who participated in discussions related to this survey. Financial support is gratefully acknowledged from NOAA Office of Global Programs Grant \#NA86GP0061, NASA EOS Grant \#OSSA-A/88, NSF STC Agreement No. EAR-98768900, the NSF Graduate Research Traineeship, UA College of Engineering and Mines Dean's Fund, and SRP Fellowship.

\section{LITERATURE CITED}

American Geophysical Union (1999) Towards improved incorporation of hydrologic research into water management practices and policies. EOS Trans 80(Suppl 17): 109-110

Anderson EA (1973) National Weather Service river forecast system-snow accumulation and ablation Model, NOAA Tech Memo HYDRO-17, NWS, Silver Spring

Anthes RA, Warner TT (1978) Development of hydrodynamic models suitable for air pollution and other mesometeorological studies. Mon Weather Rev 106:1045-1078

Bales RC (2002) Preface. In: Yarnal B (ed) CLIMAS: Climate Assessment for the Southwest. CR SPECIAL 12. Clim Res 21(3)

Barnett TP, Bengtsson L, Arpe K, Flugel M, Graham N, Latif M, Ritchie J, Roeckner E, Schlese U, Schulzweida U, Tyree M (1994) Forecasting global ENSO-related climate anomalies. Tellus 46A:381-397

Barnston AG (1994) Linear statistical short-term climate predictive skill in the northern hemisphere. J Clim 5: 1514-1564

Barnston AG (1998) Forecasts of North American surface climate using a GCM with SST boundary conditions that are forecasted by a coupled ocean-atmosphere dynamic model. Exp Long-lead Forecast Bull 7(2)

Barnston AG, Smith TM (1996) Specification and prediction of global surface temperature and precipitation from global SST using CCA. J Clim 9:2660-2697

Barnston AG, Leetma A, Kousky VE, Livezey RE, O'Lenic EA, van den Dool H, Wagner AJ, Under DA (1999) NCEP forecasts of the El Niño of 1997-98 and its U.S. impacts. Bull Am Meteorol Soc 80:1829-1852

Barnston AG, He Y, Unger DA (2000) A forecast product that maximizes utility for state-of-the-art seasonal climate prediction. Bull Am Meteorol Soc 81:1271-1279

Benequista N, James JS (1998) Pilot stakeholder assessment report. Bureau of Applied Research in Anthropology, University of Arizona, Tucson

Bengtsson L, Schlese U, Roeckner E, Latif M, Barnett TP, Graham NE (1993) A two-tiered approach to long-range climate forecasting. Science 216:1026-1029

Benjamin SG, Brown JM, Brundage KJ, Schwartz BE, Smirnova TG, Smith TL, Morone LL (1998) RUC2: the rapid update cycle version 2. Tech Proc Bull, NOAA Forecast Systems Laboratory, Boulder

Bettge TW, Baumhefner DP, Cherwin RM (1981) On the verification of seasonal climate forecasts. Bull Am Meteorol Soc 62:1654-1665

Bleck R, Benjamin SG (1993) Regional weather prediction with a model combining terrain-following and isentropic coordinates, part 1: model description. Mon Weather Rev 121:1770-1785

Borenstein S, Hansen J, Knox J, Miller R, Ruedy R, Wallace S, Wilder J (1998) Summer forecast by the GISS SI97 model based on fixed SST anomalies. Exp Long-lead Forecast Bull 7(2)

Branick M (1996) A comprehensive glossary of weather terms for storm spotters. NOAA Tech Memo NWS SR-145, 2nd edn. National Severe Storms Laboratory, Norman

Brooks HE, Witt A, Eilts MD (1997) Verification of public weather forecasts available via the media. Bull Am Meteorol Soc 78:2167-78

Burnash RJC (1995) The NWS river forecast system-catchment modeling. In: Singh VP (ed) Computer models of watershed hydrology. Water Resources Publications, Highlands Ranch, p 311-366

Burnash RJC, Ferral RL, McGuire RA (1973) A generalized streamflow simulation system-conceptual modeling for digital computers. NWS, Washington, and California Department of Water Resources, Sacramento

Cayan DR (1996) Interannual climate variability and snowpack in the western United States. J Clim 9:928-948

Cayan DR, Peterson DH (1989) The influence of North Pacific atmospheric circulation and streamflow in the West. In: Peterson DH (ed) Aspects of climate variability in the Pacific and the Western Americas. Geophys Monogr 
55, American Geophysical Union, Washington, DC, p 375-397

CBRFC (1991) Lower Colorado water supply 1991 review. CBRFC, Salt Lake City

CBRFC (1992) Water supply outlook for the Lower Colorado, March 1, 1992. CBRFC, Salt Lake City

CBRFC (1998) Snowmelt peak flow forecasts, April 1998. CBRFC, Salt Lake City

CBRFC (undated) Guide to water supply forecasting. CBRFC, Salt Lake City

Changnon D, Creech T, Marsili N, Murrell W, Saxinger M (1999) Interactions with a weather-sensitive decision maker: a case study incorporating ENSO information into a strategy for purchasing natural gas. Bull Am Meteorol Soc 80:1117-1126

Changnon SA, Vonnhame DR (1986) Use of climate predictions to decide a water management problem. Water Res Bull 22:649-652

Chen SC, Roads JO, Juang HMH, Kanamitsu M (1999) Global to regional simulation of California's wintertime precipitation. J Geophys Res D 104:31517-31532

Clayton HH (1889) Verification of weather forecasts. Am Meteorol J 6:211-219

Conley J, Eakin H, Sheridan TE, Hadley D (1999) CLIMAS ranching study: year 1. CLIMAS Rept CL2-99, Institute for the Study of Planet Earth, University of Arizona, Tucson

Côté J, Gravel S, Méthot A, Patoine A, Roch M, Staniforth A (1998) The operational CMC-MRB Global Environmental Multiscale (GEM) model: Part I-Design considerations and formulation. Mon Weather Rev 126:1373-1395

Cotton WR, Thompson G, Mielke PW Jr (1994) Real-time mesoscale prediction on workstations. Bull Am Meteorol Soc 75:349-362

Cotton WR, Thompson G, Alexander GD, Hertenstein R, Walko RL, McAnelly RL, Nicholls M (1995) Cloud venting. Earth Sci Rev 39:169-206

CPC (1995) Climate Analysis Center outlook products frequently asked questions. National Centers for Environmental Prediction, Camp Springs

CPC (1997) The climate bulletin 97(8). National Centers for Environmental Prediction, Camp Springs

CPC (2000) Long-lead outlook tool discussion and analysis. CPC, Camp Springs

Cullen MJP (1993) The unified forecast/climate model. Meteorol Mag 122:81-94

Day GN (1985) Extended streamflow forecasting using NWSRFS. ASCE J Water Res Planning Manage 111:157-170

Dudhia J, Gill D, Guo YR, Hansen D, Manning K, Wang W (1999) PSU/NCAR mesoscale modeling system tutorial class notes and users' guide. Universities Corporation for Atmospheric Research, Boulder

Dunn CM, Chadwick G (1999) Protecting study volunteers in research. CenterWatch, Boston

Garen DC (1992) Improved techniques in regression-based streamflow volume forecasting. ASCE J Water Res Planning Manage 118:654-670

Glantz MH (1982) Consequences and responsibilities in drought forecasting - the case of Yakima, 1977. Water Res Bull 18:3-13

Goddard L, Mason SJ, Zebiak SE, Ropelewski CF, Basher R (2000) Current approaches to seasonal to interannual climate predictions. Tech Rep 00-01, International Research Institute for Climate Prediction, Palisades

Hastmann HC (2001) Stakeholder driven research in a hydroclimatic context. PhD dissertation, University of Arizona

Hartmann HC, Bales R, Sorooshian S (1999) Weather, climate, and hydrologic forecasting for the Southwest U.S. CLI-
MAS Rept CL2-99, Institute for the Study of Planet Earth, University of Arizona, Tucson

Hartmann HC, Pagano TC, Sorooshian S, Bales R (2002) Confidence builders: evaluating seasonal climate forecasts from user perspectives. Bull Am Meteorol Soc 85: $1233-1250$

Higgins RW, Mo KC (1997) Persistent North Pacific circulation anomalies and the tropical intraseasonal oscillation. J Clim 10:223-244

Hogan TF, Brody LR (1993) Sensitivity studies of the Navy's Global Forecast Model parameterizations and evaluation of improvements to NOGAPS. Mon Weather Rev 121: 2373-2395

Hoke JE, Phillips NA, Dimego GJ, Tuccillo JJ, Sela JG (1989) The regional analysis and forecast system of the National Meteorological Center. Weather Fcstng 4:323-334

HPC (1997) Model biases. Hydrometeorological Prediction Center, NWS, Camp Springs

Huang J, van den Dool HM, Barnston AG (1996a) Long-lead seasonal temperature predictions using optimal climate normals. J Clim 9:809-817

Huang J, van den Dool HM, Georgakakos KG (1996b) Analysis of model-calculated soil moisture over the U.S. (1931-1993) and applications to long range temperature forecasts. J Clim 9:1350-1362

Hydrologic Research Laboratory (1998) National Weather Service river forecast system (NWSRFS) user's manual. Office of Hydrology, NWS, Silver Spring

Janzic Z (1994) The step-mountain Eta coordinate model: further developments of the convection, viscous sublayer, and turbulence closure schemes. Mon Weather Rev 122:927-945

Ji M, Kumar A, Leetma A (1994a) A multi-season climate forecast system at the National Meteorological Center. Bull Am Meteorol Soc 75:569-577

Ji M, Kumar A, Leetma A (1994b) An experimental coupled forecast system at the National Meteorological Center: some early results. Tellus 46A:398-418

Juang HMH (2000) The NCEP mesoscale spectral model: a revised version of the nonhydrostatic regional spectral model. Mon Weather Rev 128:2329-2362

Juang HMH, Kanamitsu M (1994) The NMC nested regional spectral model. Mon Weather Rev 122:3-26

Juang HMH, Hong S, Kanamitsu M (1997) The NCEP regional spectral model: an update. Bull Am Meteorol Soc 78:2125-2143

Junker W (1998) The performance of the NCEP operational models from an HPC perspective. Hydrometeorological Prediction Center, NWS, Camp Springs

Kalnay E, Kanamitsu M, Baker WE (1990) Global numerical weather prediction at the National Meteorological Center. Bull Am Meteorol Soc 71:1410-1428

Kalnay E and 21 others (1996) The NCEP/NCAR 40-year reanalysis project. Bull Am Meteorol Soc 77:437-471

Kerr RA (1990) Who can forecast the worst weather? Science 250:29-31

Kiehl JT, Hack JJ, Bonan GB, Boville BA, Briegleb BP, Williamson DL, Rasch PJ (1996) Description of the NCAR community climate model (CCM3). NCAR Tech Note TN420+STR, National Center for Atmospheric Research, Boulder

Kiehl JT, Hack JJ, Hurrell JW (1998) The energy budget of the NCAR community climate model: CCM3. J Clim 11: 1151-1178

Kohler MA, Linsley RK (1951) Predicting the runoff from storm rainfall. US Weather Bur Res Pap 34, Washington, DC 
Leetma A (1998) Forecasts of the 1997-98 El Niño: what was forecasted and what happened. California Workshop on Regional Climate Variability and Change, Office of Global Programs, NOAA, Santa Barbara, CA, 10 March 1998

Lehman RL (1987) A model for decision making based on NWS monthly temperature outlooks. J Clim Appl Meteorol 26:263-274

Linsley RK, Kohler MA, Paulhus JLH (1975) Hydrology for engineers, 2nd edn. McGraw-Hill, New York

Liverman D, Merideth R (2002) Climate and society in the Southwest: the context for a regional assessment. In: Yarnal B (ed) CLIMAS: Climate Assessment for the Southwest. CR SPECIAL 12. Clim Res 21:199-218

Livezey RE (1990) Variability of skill of long-range forecasts and implications for their use and value. Bull Am Meteorol Soc 71:300-309

Livezey RE, Masutani M, Ji M (1996) SST-forced seasonal simulation and prediction skill for versions of the NCEP/MRF model. Bull Am Meteorol Soc 77:507-517

Livezey RE, Masutani M, Leetma A, Rui H, Ji M, Kumar A (1997) Teleconnective response of the Pacific-North American region atmosphere to large central equatorial Pacific SST anomalies. J Clim 10:1787-1820

Maidment DR (ed) (1993) Handbook of hydrology. McGrawHill, New York

Mason SJ, Goddard L, Graham NE, Yulaeva E, Sun L, Arkin P (1999) The IRI seasonal climate prediction system and the 1997/98 El Niño event. Bull Am Meteorol Soc 80: 1853-1873

McCuen RH, Rawls WJ, Whaley BL (1979) Comparative evaluation of statistical methods for water supply forecasting. Water Res Bull 15:933-947

Mittelstadt J (1997) Current and upcoming changes to the Eta models. Western Regional Tech Attach No 97-06, NWS Forecast Office, Salt Lake City

Mjelde JW, Peel DS, Sonka ST, Lamb PL (1993) Characteristics of climate forecast quality: implications for economic value to midwestern corn producers. J Clim 6:2175-2187

Murphy AH, Huang J (1991) On the quality of CAC's probabilistic 30-day and 90-day forecasts. In: Proc 16th Annual Climate Diagnostics and Prediction Workshop. PB92167378, Natl Tech Info Serv, Springfield, p 390-399

National Meteorological Center (1988) Documentation of the research version of the NMC medium-range forecasting model. Development Division, NWS, Camp Springs

Nemec J, Sittner WT (1982) Application of the continuous API catchment model in the Indus River forecasting system in Pakistan. In: Singh VP (ed) Applied modeling in catchment hydrology. Water Resources Publications, Highlands Ranch, p 313-322

Nicholls N (1999) Cognitive illusions, heuristics, and climate prediction. Bull Am Meteorol Soc 80:1385-1398

NWS (1995) Weather service operation manual (WSOM), part C: basic/public weather services, zone and local forecasts, 95-3. National Weather Service, Camp Springs

Oberhuber JM (1993) Simulation of the Atlantic circulation with a coupled sea ice-mixed layer-isopycnal general circulation model. Part 1: model description. J Phys Oceanogr 23:808-829

Office of Global Programs (1999) An experiment in the application of climate forecasts: NOAA-OGP activities related to the 1997-98 El Niño event. Universities Corporation for Atmospheric Research, Boulder

Office of Hydrology (1996) Hydrometeorological service operations for the 1990's. National Weather Service, Silver Spring

Pagano TC, Hartmann HC, Sorooshian S, Bales R (1999)
Advances in seasonal forecasting for water management in Arizona: a case study of the 1997-98 El Niño. Tech Rep HWR 99-040, Department of Hydrology and Water Resources, University of Arizona, Tucson

Pagano TC, Hartmann HC, Sorooshian S (2002) The role and usability of climate forecasts for water management in Arizona: a case study of the 1997-98 El Niño. In: Yarnal B (ed) CLIMAS: Climate Assessment for the Southwest. CR SPECIAL 12. Clim Res 21:259-269

Peng P, Kumar AG, Barnston AG, Goddard L (2000) Simulation skills of the SST-forced global climate variability of the NCEP-MRF9 and the Scripps/MPI ECHAM3 models. J Clim 13:3657-3679

Perica S (1998) Integration of meteorological forecasts/climate outlooks into an ensemble streamflow prediction system. In: Proc 14th Conference on Probability and Statistics in the Atmospheric Sciences. American Meteorological Society, Boston, p 130-133

Pielke RA (1985) The use of mesoscale numerical models to assess wind distribution and boundary-layer structure in complex terrain. Boundary Layer Meteorol 31:217-231

Pielke RA, Cotton WR, Walko RL, Tremback CJ and 7 others (1992) A comprehensive meteorological modeling system-RAMS. Meteorol Atmos Phys 49:69-91

Pierce DW (1996) The hybrid coupled model, version 3: technical notes. SIO Ref Ser No. 96-27, Scripps Institute of Oceanography, San Diego

Priesendorfer RW, Mobley CD (1984) Climate forecast verification, United States mainland, 1974-83. Mon Weather Rev 112:809-825

Redmond K, Koch R (1991) Surface climate and streamflow variability in the western United States and their relationship to large-scale circulation indices. Water Res Res 27:2381-2399

Roads JO, Chen SC, Kanamitsu M, Juang H (1999) Surface water characteristics in the NCEP Global Spectral Model and reanalysis. J Geophys Res 104:19307-19325

Rogers E, Deaven DG, Dimego GJ (1995) The regional-analysis system for the operational early Eta-model-original $80-\mathrm{km}$ configuration and recent changes. Weather Forecasting 10:810-825

Rosmond TE (1992) The design and testing of the Navy Operational Global Atmospheric Prediction System. Weather Forecasting 7:262-272

Rubin HJ, Rubin IS (1995) Qualitative interviewing: the art of hearing data. Sage Publications, Thousand Oaks

Sarewitz D, Pielke RA Jr, Byerly R (eds) (2000) Prediction: science, decision making, and the future of nature. Island Press, Covelo

Schaefer JT, Livingston RL (1990) Operational implications of the 'probability of precipitation'. Weather Forecasting 5: 354-356

Soil Conservation Service (1985) National engineering handbook. Department of Agriculture, Washington

Soil Conservation Service (1986) Urban hydrology for small watersheds: TR-55. Tech Release No. 55, Department of Agriculture, Washington, DC

Soil Conservation Service and NWS (1994) Water supply outlook for the western United States. West National Technical Center, Soil Conservation Service, Portland

SRP (1998) Weather and climate forecasting at SRP: summary for the forecast assessment workshop. SRP, Phoenix

Shafer BA, Huddleston JM (1984) Analysis of seasonal volume streamflow forecast errors in the western United States. In: A critical assessment of forecasting in water quality goals in western water resources management. American Water Resources Association, Bethesda, p 117-126 
Staudenmaier MJ (1996a) A description of the meso Eta model. Western Reg Tech Attach 96-06, NWS Forecast Office, Salt Lake City

Staudenmaier MJ (1996b) The convective parameterization scheme in the meso Eta model. Western Reg Tech Attach 96-23, NWS Forecast Office, Salt Lake City

Staudenmaier MJ (1996c) The explicit cloud prediction scheme in the meso Eta model. Western Reg Tech Attach 96-29, NWS Forecast Office, Salt Lake City

Staudenmaier MJ (1996d) The initialization procedure in the meso Eta model. Western Reg Tech Attach 96-30, NWS Forecast Office, Salt Lake City

Staudenmaier MJ (1997a) The benefits of higher resolution in representing topography. Western Reg Tech Attach 97-01, NWS Forecast Office, Salt Lake City

Staudenmaier MJ (1997b) Why is high resolution important in the West? An early look at the Eta-10 model output. Western Reg Tech Attach 97-03, NWS Forecast Office, Salt Lake City

Staudenmaier MJ (1997c) The soil model in the Eta. Western Reg Tech Attach 97-07, NWS Forecast Office, Salt Lake City

Staudenmaier MJ (1997d) The Navy Operational Global Atmospheric Prediction Systems (NOGAPS). Western Reg Tech Attach 97-09, NWS Forecast Office, Salt Lake City

Stern PC, Easterling WE (1999) Making climate forecasts matter. National Academy Press, Washington, DC

Unger DA (1996a) Long lead climate prediction using screening multiple linear regression. In: Proc 20th Annual Climate Diagnostics Workshop. National Centers for Envi-

Submitted: May 11, 2000; Accepted: February 27, 2002 ronmental Prediction, Silver Spring, p 425-428

Unger DA (1996b) Forecasts of surface temperature and precipitation anomalies over the U.S. using screening multiple linear regression. Exp Long-Lead Forecast Bull $5(2)$

van Bussem L Jr (1999) A composite look at weather surveys: using several weather surveys to get an estimate of public opinion. Western Reg Tech Attach 99-20, NWS Forecast Office, Sacramento

Whyte AVT (1977) Guidelines for field studies in environmental perception. United Nations Educational, Scientific and Cultural Organization, Paris

Wilder J, Beckford K, Borenstein S, Druyan L, Estrella A, Hansen J, Knox J, Miller R, Ruedy R (1997) Winter forecast by the GISS SI97 model based on fixed SST anomalies. Exp Long-lead Forecast Bull 6(4)

Wilks DS (2000) Diagnostic verification of the Climate Prediction Center long-lead outlooks, 1995-1998. J Clim 13: 2389-2403

Woods A (1997) ECMWF operational deterministic forecasting system, December 1996-a summary. European Center for Medium-range Weather Forecasts, Reading

Woodhouse CA (1997) Winter climate and atmospheric circulation patterns in the Sonoran Desert region. Int J Clim 17: 859-873

WRCC (1998) Long-lead climate outlook frequently asked questions. Western Regional Climate Center, Desert Research Institute, Reno

Yankee Publishing (2000) The old farmer's almanac. Yankee Publishing, Dublin

Proofs received from author(s): April 23, 2002 